\title{
Compliance of Public Elementary Schools with the Enhanced School Improvement Plan
}

\author{
Lawrence Jerome P. Granada \\ Department of Education, Schools Division of Bacolod City \\ lawrencejerome.granada@deped.gov.ph
}

\begin{abstract}
This descriptive-comparative research was conducted to determine the compliance level of public elementary schools in Bacolod City Division with the Enhanced School Improvement Plan (E-SIP) as assessed by internal and external assessors when taken as a whole and when compared according to school demographics in the major phases of E-SIP development and implementation process. Likewise, it detailed the challenges and actions undertaken in the E-SIP compliance. Using the standardized SIP quality assessment tool, the results revealed a 'satisfactory' level of E-SIP compliance as whole while 'highly satisfactory' levels in plan and act phases. It further showed significant differences on preparatory, assess and act phases for both school performance and designation of assessors. The results of assessment were attributed to varying interpretation of some criteria and the absence of mode of verification in the E-SIP compliance. Hence, a policy recommendation was designed to attain successful E-SIP compliance of public elementary schools.
\end{abstract}

Keywords: Enhanced School Improvement Plan (E-SIP), E-SIP Compliance, Public Elementary Schools, Bacolod City, Philippines 